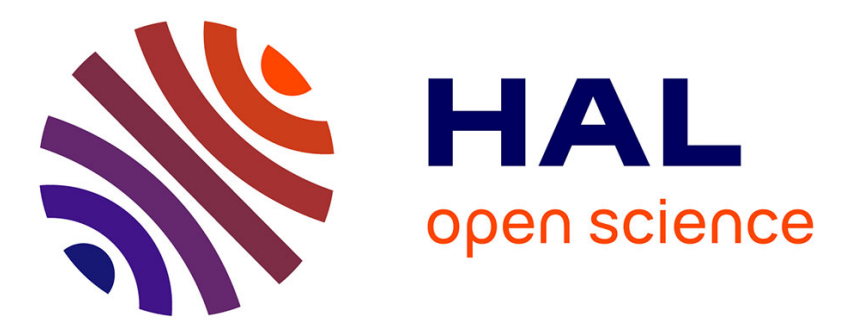

\title{
Metallic nanoparticle-based strain sensors elaborated by atomic layer deposition
}

Etienne Puyoo, Christophe Malhaire, Daniel Thomas, Rémi Rafael, Mohamed R'Mili, Annie Malchere, Lucian Roiban, Siddardha Koneti, Matthieu Bugnet, Andreï Sabac, et al.

\section{To cite this version:}

Etienne Puyoo, Christophe Malhaire, Daniel Thomas, Rémi Rafael, Mohamed R'Mili, et al.. Metallic nanoparticle-based strain sensors elaborated by atomic layer deposition. Applied Physics Letters, 2017, 110, pp.123103. 10.1063/1.4978778 . hal-01701521

\section{HAL Id: hal-01701521 \\ https://hal.science/hal-01701521}

Submitted on 5 Jun 2018

HAL is a multi-disciplinary open access archive for the deposit and dissemination of scientific research documents, whether they are published or not. The documents may come from teaching and research institutions in France or abroad, or from public or private research centers.
L'archive ouverte pluridisciplinaire HAL, est destinée au dépôt et à la diffusion de documents scientifiques de niveau recherche, publiés ou non, émanant des établissements d'enseignement et de recherche français ou étrangers, des laboratoires publics ou privés. 


\title{
Metallic nanoparticle-based strain sensors elaborated by atomic layer deposition
}

\author{
E. Puyoo, ${ }^{1, \text { a) }}$ C. Malhaire,${ }^{1}$ D. Thomas,${ }^{1}$ R. Rafaël, ${ }^{1}$ M. R'Mili, ${ }^{2}$ A. Malchère,${ }^{2}$ L. Roiban, ${ }^{2}$ \\ S. Koneti, ${ }^{2}$ M. Bugnet ${ }^{2}$ A. Sabac, ${ }^{1}$ and M. Le Berre ${ }^{1}$ \\ ${ }^{1}$ Institut des Nanotechnologies de Lyon, Université de Lyon, INL UMR 5270, CNRS, INSA de Lyon, \\ Villeurbanne F-69621, France \\ ${ }^{2}$ MATEIS Laboratory, Université de Lyon, MATEIS UMR 5510, CNRS, INSA de Lyon, \\ Villeurbanne F-69621, France
}

Platinum nanoparticle-based strain gauges are elaborated by means of atomic layer deposition on flexible polyimide substrates. Their electro-mechanical response is tested under mechanical bend-ing in both buckling and conformational contact configurations. A maximum gauge factor of 70 is reached at a strain level of $0.5 \%$. Although the exponential dependence of the gauge resistance on strain is attributed to the tunneling effect, it is shown that the majority of the junctions between adjacent $\mathrm{Pt}$ nanoparticles are in a short circuit state. Finally, we demonstrate the feasibility of an all-plastic pressure sensor integrating Pt nanoparticle-based strain gauges in a Wheatstone bridge configuration.

An important part of the MEMS (Micro-ElectroMechanical System) market is currently driven by the manufacturing of various sensors (pressure sensors, microphones, and inertial sensors) which use piezoresistive transducers based on monocrystalline silicon. ${ }^{1}$ For the last ten years, the research on piezoresistive transducers has mainly been focused on the use of nanomaterials to optimize sensitivity, power consumption, and sensor miniaturization. For instance, $\mathrm{Si}$ nanowires, ${ }^{2-4}$ carbon nanotubes, ${ }^{5-7}$ graphene $,{ }^{8-10} \mathrm{MoS}_{2},{ }^{10} \mathrm{SiC}$ nanoribbons,${ }^{11} \mathrm{Ag}$ nanowires, ${ }^{12}$ and metallic nanoparticle (NP) assemblies ${ }^{13-20}$ have been exploited at the laboratory scale to achieve very large gauge factors (GFs) which rival the state-of-the-art bulk Si gauges. Although the use of nanomaterials has attracted a lot of attention in the literature these past few years, many technological obstacles (manipulation of individual nanostructures, complexity of the process, sensor reproducibility, etc.) have yet to be overcome to make nanomaterials the preferred material for strain sensors. Consequently, alternative reliable technologies for the fabrication of nanostructured strain gauges with high GF are still sought by the industry. In this work, metallic NP-based strain sensors are elaborated by means of Atomic Layer Deposition (ALD) on flexible substrates. According to the literature, the high sensitivity of metallic NP strain gauges is attributed to the modulation, with respect to the strain, of electron tunnelling events between neighbouring NPs. ${ }^{13-20}$ These metallic NP strain sensors are usually elaborated from colloidal solutions which are transferred to a variety of substrates by inkjet printing, airbrush spraying, layer-by-layer deposition, centrifugal method, or convective self-assembly. ${ }^{13-16,18-20}$ However, such processes are unconventional for the silicon industry, and therefore, they cannot address traditional MEMS applications. These processes are indeed rather suited for the

\footnotetext{
${ }^{\text {a) }}$ Author to whom correspondence should be addressed. Electronic mail: etienne.puyoo@insa-lyon.fr
}

development of flexible and stretchable electronic devices integrated on low-cost polymer substrates. In our opinion, capitalizing on ALD to grow both metallic NPs and dielectric tunnel barriers provides a greater flexibility for both standard MEMS integration and flexible/stretchable electronics and could therefore represent an easier path to adoption by the industry.

Here, platinum $(\mathrm{Pt})$ NPs were grown by Plasma Enhanced ALD (PEALD) from the (methylcyclopentadienyl)-trimethyl platinum $\left(\mathrm{MeCpPtMe}_{3}\right)$ precursor (pulse and purge durations of $1 \mathrm{~s}$ and $10 \mathrm{~s}$, respectively) and $\mathrm{O}_{2}$ plasma $\left(300 \mathrm{~W}\right.$ power during $20 \mathrm{~s}$ with an $\mathrm{O}_{2}$ flow of $20 \mathrm{sccm})$ on thermal ALD alumina $\left(\mathrm{Al}_{2} \mathrm{O}_{3}\right)^{21,22}$ in subsequent process steps at $200^{\circ} \mathrm{C}$ in an Ultratech FIJI F200 reactor. Figure 1(a) is a bright field TEM (Transmission Electron Microscopy) image of Pt NPs grown on a $5 \mathrm{~nm}$ thick $\mathrm{Al}_{2} \mathrm{O}_{3}$ film. The $\mathrm{Al}_{2} \mathrm{O}_{3}$ thin film was first deposited at $200^{\circ} \mathrm{C}$ from trimethyl aluminium (TMA) and $\mathrm{H}_{2} \mathrm{O}$ precursors (pulse and purge durations of $60 \mathrm{~ms}$ and $10 \mathrm{~s}$, respectively, for both precursors) on an $8 \mathrm{~nm}$ thick $\mathrm{SiO}_{2}$ TEM grid. 50 successive ALD cycles were needed to obtain this $5 \mathrm{~nm}$ thick $\mathrm{Al}_{2} \mathrm{O}_{3}$ layer. The Pt NPs were then grown on $\mathrm{Al}_{2} \mathrm{O}_{3}$ in the same PEALD reactor and at the same temperature. The Pt NP assembly presented in Figure 1(a) corresponds to 45 subsequent PEALD cycles. From the distribution plot presented in the inset of Figure 1(a), we determined a Pt NP average diameter of $3.1 \mathrm{~nm}$ and a standard deviation of $0.9 \mathrm{~nm}$. It should be noted that we could modulate the Pt NP average diameter from $1.5 \mathrm{~nm}$ to $5 \mathrm{~nm}$ on different samples by simply varying the number of PEALD cycles from 30 to 60 cycles.

In order to fabricate the metallic nanoparticle-based strain sensors, we have stacked several Pt NP layers and $\mathrm{Al}_{2} \mathrm{O}_{3}$ tunnel oxide layers, both deposited by ALD in the same reactor. Figure 1(b) is a High angle annular dark field (HAADF)- Scanning Transmission Electron Microscopy (STEM) cross section image of a Pt NP-based strain gauge integrated on a $75 \mu \mathrm{m}$ thick polyimide (Dupont ${ }^{\mathrm{TM}}$ Kapton $^{\circledR}$ 
a)

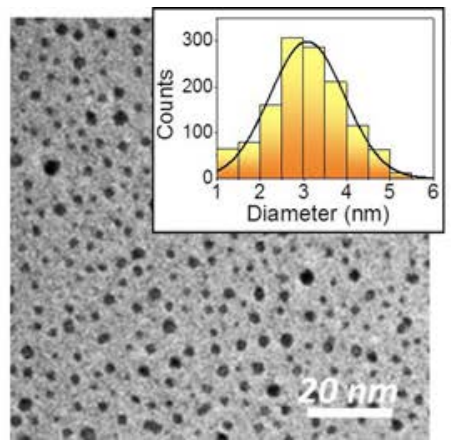

b)

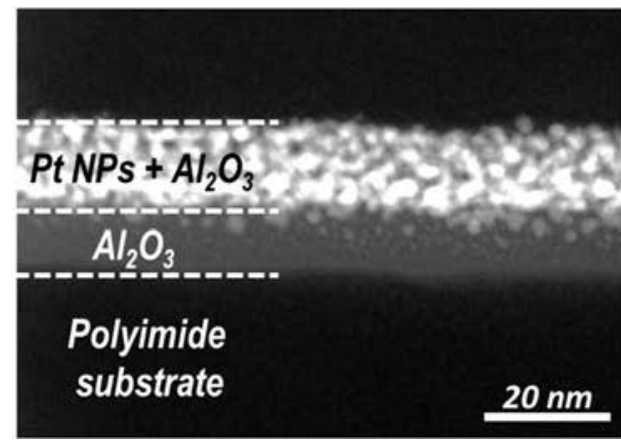

c)

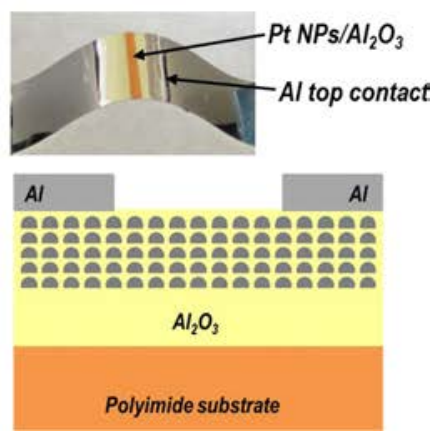

FIG. 1. (a) Bright field transmission electron microscopy image of Pt nanoparticles grown on a $5 \mathrm{~nm}$ thick $\mathrm{Al}_{2} \mathrm{O}_{3}$ film. Inset shows the diameter distribution plot of the Pt NPs. (b) High angle annular dark field-Scanning Transmission Electron Microscopy cross section image of a Pt NP-based strain gauge integrated on a flexible polyimide substrate. (c) Photograph and schematic illustration of a complete flexible strain sensor.

$\mathrm{HN}$ ) flexible substrate. In this STEM image, we can observe a $15 \mathrm{~nm}$ thick $\mathrm{Pt} \mathrm{NPs} / \mathrm{Al}_{2} \mathrm{O}_{3}$ composite layer which was deposited on an $\mathrm{Al}_{2} \mathrm{O}_{3} /$ polyimide substrate. In order to ensure the nucleation and growth of Pt NPs, we have indeed first deposited a $10 \mathrm{~nm}$ thick $\mathrm{Al}_{2} \mathrm{O}_{3}$ film on the polyimide substrate. Then, the $\mathrm{Pt} \mathrm{NPs} / \mathrm{Al}_{2} \mathrm{O}_{3}$ sensitive layer was obtained by intercalating five 50 cycles Pt NPs layers in between five 12 cycles $\mathrm{Al}_{2} \mathrm{O}_{3}$ tunnel oxide layers. From Figure 1(b), we can roughly observe that the Pt NPs have diameters inferior to $5 \mathrm{~nm}$ which is consistent with the results presented in Figure 1(a). Moreover, by considering that the $\mathrm{Al}_{2} \mathrm{O}_{3}$ growth rate is $0.1 \mathrm{~nm}$ per cycle, the $\mathrm{Al}_{2} \mathrm{O}_{3}$ dielectric tunnel barriers which were intercalated between neighbouring Pt NPs layers should have a thickness of around $1.2 \mathrm{~nm}$. Finally, aluminum top contacts were patterned on top of the active multilayer by electron beam evaporation through solid shadow masks. For the sake of clarity, a photograph and a schematic illustration of a complete flexible strain sensor are presented in Figure 1(c).

In order to study the electro-mechanical response of the Pt NP-based strain gauges, rectangular samples $(10 \mathrm{~mm} \times 75 \mu \mathrm{m}$ cross section) were subjected to tensile strains by mechanical bending in two different configurations: buckling (see the photograph series in Fig. 2(a)) and conformational contact with
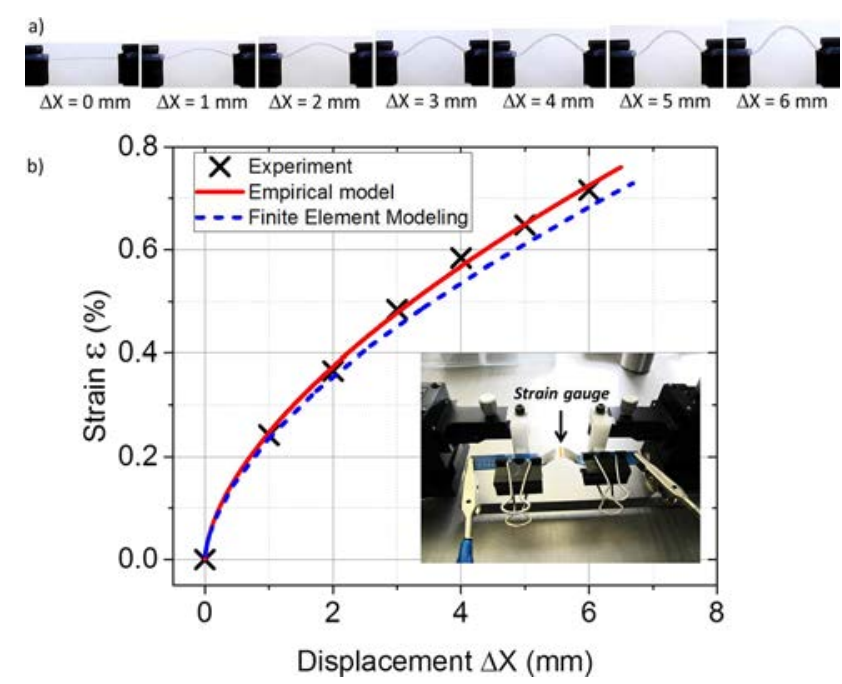

FIG. 2. (a) Photograph series of the flexible strain sensor for displacements $\Delta X$ ranging from $0 \mathrm{~mm}$ to $6 \mathrm{~mm}$. (b) Calibration curve of the buckling test bench (Inset: photograph of the buckling test bench). cylindrical sample holders of different diameters. Concerning the buckling configuration, we have first calibrated the test bench which consists of two micro-manipulators on which the flexible strain sensor is attached (see inset in Fig. 2(b)). After mounting the sample, the distance between the clamps was $28 \mathrm{~mm}$. As presented in the photograph series of Figure 2(a), the radius of curvature at the centre of the bended strain gauge was adjusted by simply decreasing the distance $\mathrm{X}$ between the two micro-manipulators. The radius of curvature could be modulated from infinity to $0.5 \mathrm{~cm}$ by varying the displacement $\Delta \mathrm{X}$ from 0 to $6 \mathrm{~mm}$ (Fig. 2(a)). The resulting tensile strain $\varepsilon$ could be estimated by the following expression: ${ }^{13,14}$

$$
\varepsilon=\frac{t}{t+2 r_{c}},
$$

where $r_{c}$ is the radius of curvature in the centre of the gauge (measured on images in Fig. 2(a)) and the thickness of the polyimide substrate $(\mathrm{t}=75 \mu \mathrm{m})$. In addition, in order to check the validity of Eq. (1), finite element simulations were performed with Ansys ${ }^{\circledR} 16.2$ software. Due to symmetries, only a quarter of the polyimide beam was meshed using quadrilateral SOLID186 elements with Young's modulus and Poisson's ratio values of $3.4 \mathrm{GPa}$ (measured from a stress-strain test) and 0.34 , respectively. A pressure, increased by successive steps up to $1000 \mathrm{mbar}$, was applied to one end of the beam (in fact two because of symmetry, and only longitudinal displacements were allowed at the corresponding nodes), while a low pressure of $1 \mathrm{mbar}$ was applied below the beam so that it buckles up. For each step, the surface longitudinal strain at the middle of the beam and the displacement at its end were obtained.

The calibration curve of the buckling test bench is presented in Figure 2(b). Tensile strains up to $0.7 \%$ could be applied with a maximum displacement of $6 \mathrm{~mm}$. This calibration curve could be fitted with an empirical model $\left(\varepsilon=(\alpha \times \Delta \mathrm{X})^{\beta}\right.$, with $\alpha \approx 0.047 \mathrm{~m}^{-1}, \beta \approx 0.6$, and $\left.\mathrm{R}^{2}>0.997\right)$ and is in agreement with Finite Element Modelling (Fig. 2(b)).

Figure 3(a) presents a series of Current-Voltage (I(V)) measurements performed with a Keithley ${ }^{\circledR} 4200$-SCS system in the buckling configuration with different applied tensile strains up to $0.5 \%$. From the linear $\mathrm{I}(\mathrm{V})$ curves carried out without any external strain, we could estimate a resistivity of $2.8 \times 10^{4} \Omega \mathrm{cm}$ for the $\mathrm{Pt} \mathrm{NPs} / \mathrm{Al}_{2} \mathrm{O}_{3}$ composite thin film 
a)

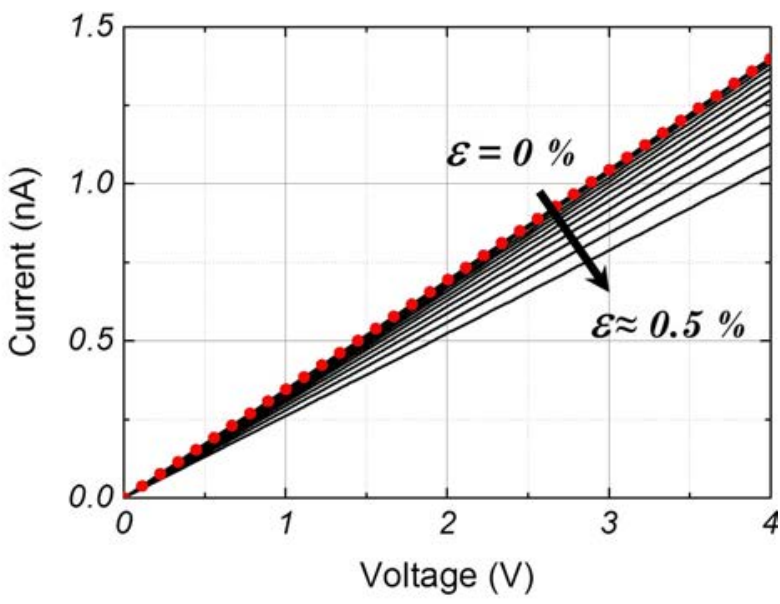

b)

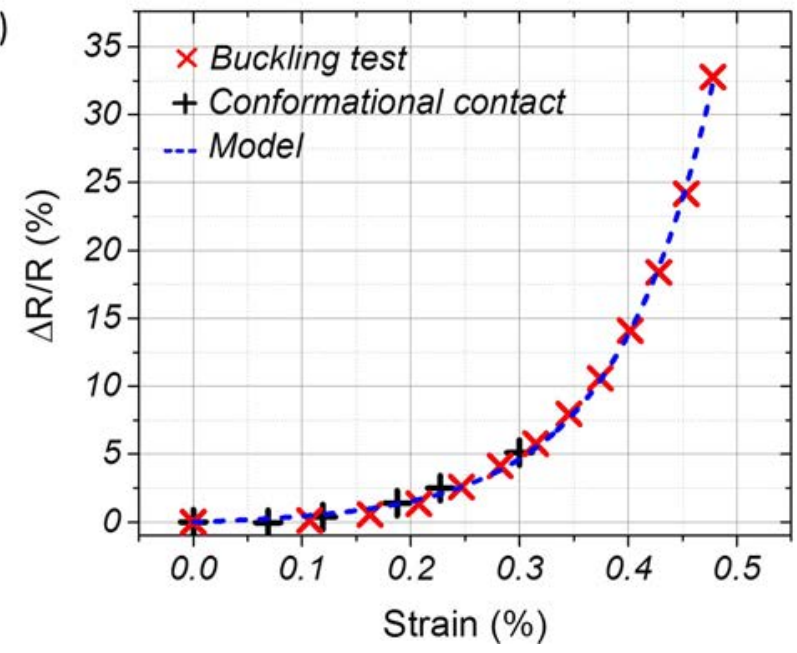

FIG. 3. (a) Current-voltage characteristics performed in buckling mode with different applied tensile strains up to $0.5 \%$. (b) The relative variation of resistance $\Delta \mathrm{R} / \mathrm{R}$ as a function of tensile strain $\varepsilon$ obtained in the buckling mode and in the conformational contact configuration.

which is around 9 orders of magnitude higher than the resistivity of bulk Pt. This high electrical resistivity indicates that the electron transport is most likely limited at the junctions between adjacent Pt NPs which suggests the presence of high contact resistances and/or high tunnel resistances between NPs. A clear decrease in the current level is evident from Fig. 3(a) when the tensile strain level is increased up to $0.5 \%$. We can also observe that the $\mathrm{I}(\mathrm{V})$ characteristics remain linear for tensile strain values ranging from $0 \%$ to $0.5 \%$, which possibly means that the electron transport mechanism is unchanged with external strain in the buckling configuration. Note that the red doted $\mathrm{I}(\mathrm{V})$ characteristic presented in Fig. 3(a) has been carried out without any applied strain after 13 successive measurements performed with different tensile strains from $0 \%$ to $0.5 \%$. This red doted curve in Fig. 3(a) is perfectly superimposed on the first measured black $\mathrm{I}(\mathrm{V})$ characteristic (also performed without any strain) which shows the reproducibility of the measurement.

The relative variations of resistance $\Delta R / R$ with tensile strain $\varepsilon$ obtained in the buckling mode and in the conformational contact configuration are both presented in Fig. 3(b). Concerning the conformational contact configuration, we have measured the electrical resistance of a $1 \mathrm{~cm} \times 1 \mathrm{~cm}$ strain gauge which was sequentially fixed on 5 different cylindrical sample holders with curvature radii $r_{c}$ ranging from $12.5 \mathrm{~mm}$ to $53 \mathrm{~mm}$. The corresponding applied external strains were again estimated from Eq. (1). A good agreement is observed in Fig. 3(b) between these two measurement configurations. At a strain of $0.5 \%$, a sensitivity $\frac{\Delta R / R}{\varepsilon}$ of 70 is reached which is comparable to that of the NP-based strain gauges elaborated from colloidal solutions. ${ }^{13,14,17,19,20}$ As previously suggested in the literature, ${ }^{13-20}$ the exponential increase of $\Delta \mathrm{R} / \mathrm{R}$ with tensile strain $\varepsilon$ which is observed in Fig. 3(b) is consistent with the exponential dependence of tunnelling resistance on the interparticle separation distance. However, the fact that the sensitivity remains relatively low (i.e., $\frac{\Delta R / R}{\varepsilon}<10$ ) at low strain (i.e., $\varepsilon<0.2 \%$ ) possibly indicates that a non-negligible proportion of the $\mathrm{Pt} / \mathrm{Al}_{2} \mathrm{O}_{3} / \mathrm{Pt}$ junctions are in short circuit state.

In order to model the electro-mechanical response of the Pt NP-based strain sensor, we propose here to consider that the total resistance $\mathrm{R}$ of the $\mathrm{Pt} \mathrm{NPs} / \mathrm{Al}_{2} \mathrm{O}_{3}$ composite gauge is the sum of 2 contributions

$$
R=R_{T}+R_{\Omega},
$$

where $\mathrm{R}_{\Omega}$ represents the ohmic contribution of the interconnected Pt NPs and $R_{T}$ represents the tunnelling contribution of the rest of the $\mathrm{Pt} / \mathrm{Al}_{2} \mathrm{O}_{3} / \mathrm{Pt}$ junctions which are operational tunnel junctions.

Without any applied external strain, the total resistance $\mathrm{R}_{0}$ of the strain gauge is given by

$$
R_{0}=\left(R_{\Omega}\right)_{0}+\left(R_{T}\right)_{0}=x R_{0}+(1-x) R_{0},
$$

where the index 0 refers to a tensile strain of $0 \%$ and $\mathrm{x}$ is the ratio $\left(\mathrm{R}_{\Omega}\right)_{0} / \mathrm{R}_{0}$.

By considering that the change of the ohmic contribution is only due to geometric effects, the relative variation of $\mathrm{R}_{\Omega}$ as a function of strain $\varepsilon$ can be expressed by the following expression: ${ }^{1}$

$$
\frac{\Delta R_{\Omega}}{\left(R_{\Omega}\right)_{0}}=(1+2 \nu) \varepsilon
$$

where $\nu$ is the Poisson's ratio of the strain gauge. Note that the eventual change in resistivity due to strain of the interconnected metallic NPs has been neglected in Eq. (4).

According to the simplified electron tunneling model which was used in many different recent studies on NPbased strain gauges, the relative resistance change with strain of the tunneling contribution $\mathrm{R}_{\mathrm{T}}$ can be expressed as ${ }^{13,14,19,20}$

$$
\frac{\Delta R_{T}}{\left(R_{T}\right)_{0}}=\exp (g \varepsilon)-1,
$$

where $\mathrm{g}$ is a constant commonly defined as the gauge factor which characterizes the sensitivity of NP-based strain sensors. It should be noted that all the junctions are considered parallel to the deformation in Eqs. (4) and (5).

Finally, by combining Equations (2), (3), (4) and (5), the total relative resistance change $\Delta \mathrm{R} / \mathrm{R}_{0}$ with strain $\varepsilon$ can be described as follows:

$$
\frac{\Delta R}{R_{0}}=x(1+2 \nu) \varepsilon+(1-x)(\exp (g \varepsilon)-1) .
$$


Eq. (6) was used to fit the experimental data presented in Fig. 3(b). For extracted $x$ and $g$ values of $99.8 \%$ and 1100 , respectively, this simple model properly matches the electro-mechanical response of the Pt NP-based strain gauge (Fig. 3(b)). This good agreement confirms first that the majority of the $\mathrm{Pt} / \mathrm{Al}_{2} \mathrm{O}_{3} / \mathrm{Pt}$ junctions are in the short circuit state. Moreover, it corroborates the fact that the exponential dependence of the gauge resistance with strain is due to tunnelling effects between neighbouring NPs. It should be noted that much better sensitivities could be reached by minimizing the number of junctions which are in a short circuit state. In our opinion, these shorts can be due to a bad conformity of the $\mathrm{Al}_{2} \mathrm{O}_{3}$ tunnel oxide layers which do not completely cover the Pt NPs or to the presence of defects within the $\mathrm{Al}_{2} \mathrm{O}_{3}$ tunnel oxide which behave as conductive pathways for electrons between adjacent NPs. We therefore believe that this ohmic contribution could be reduced in the future by optimizing our ALD process to grow conformal and defect-free $\mathrm{Al}_{2} \mathrm{O}_{3}$ tunnel oxide layers.

Finally, we have taken advantage of the low temperature ALD process (performed at $200{ }^{\circ} \mathrm{C}$ ) to develop an all-plastic pressure sensor integrating Pt NP-based strain gauges. As depicted in Fig. 4(a), four gauges have been integrated in a Wheatstone quarter-bridge configuration on a $75 \mu \mathrm{m}$ thick polyimide substrate. This $75 \mu \mathrm{m}$ thick polyimide film (acting as a membrane) was then stuck on a $2 \mathrm{~mm}$ thick plastic substrate with a $3 \times 3 \mathrm{~mm}^{2}$ squared hole in its centre. Only one of the four gauges was placed above the hole in order to sense any differential pressure applied underneath the polyimide membrane. Figure 4 (b) presents the $V_{\text {out }}$ response of

a)

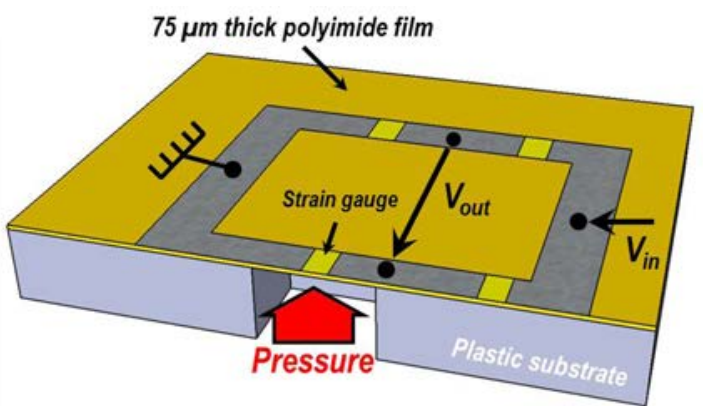

b)

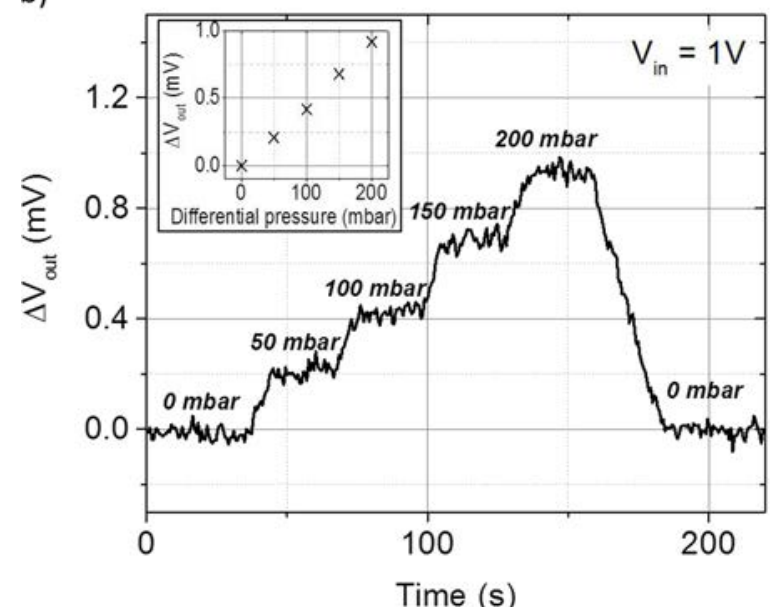

FIG. 4. (a) Schematic illustration of the plastic pressure sensor integrating Pt NP-based strain gauges. (b) $\mathrm{V}_{\text {out }}$ response of the sensor as a function of pressure in the [0-200] mbar range. the sensor as a function of pressure in the [0-200] mbar range ( 50 mbar per step) for an input voltage $V_{\text {in }}$ of $1 \mathrm{~V}$ (Fig. 4(b)). A good linearity is observed (see inset in Fig. 4(b)) with a sensitivity of $4.75 \times 10^{-3}$ bar $^{-1}$ which rivals state-ofthe-art $\mathrm{Si}$ technology-based pressure sensors integrating graphene strain gauges. ${ }^{10}$ Although the sensitivity could be further increased by optimizing the design of our pressure sensor (membrane thickness, size, and position of the gauges...), this demonstrates the feasibility of an all-plastic MEMS device integrating Pt NP-based strain gauges.

In this paper, we have investigated the electromechanical response of Pt NP-based strain gauges elaborated with a low temperature ALD process. Comparable sensitivities to that of the NP-based strain gauges elaborated from colloidal solutions were achieved under mechanical bending in buckling and conformational contact configurations. However, we have highlighted that this good sensitivity to strain was hindered by a high proportion of short circuited $\mathrm{Pt} / \mathrm{Al}_{2} \mathrm{O}_{3} / \mathrm{Pt}$ junctions between neighbouring NPs. Finally, we have demonstrated the feasibility of our low temperature ALD process to develop a high sensitivity all-plastic MEMS pressure sensor. Future works will concern the optimization of the ALD process by varying the NP morphology and the thickness of the $\mathrm{Al}_{2} \mathrm{O}_{3}$ tunnel oxide.

This work was funded by a Bonus Qualité Recherche grant from INSA Lyon. The samples were processed on the Nanolyon technological platform of Lyon Institute of Nanotechnologies. The authors thank Khaled Ayadi and Joëlle Grégoire for their technical support on this project. The authors also acknowledge the CLYM center for the access to the FEI TITAN-ETEM $80-300 \mathrm{keV}$ and JEOL 2010F microscopes.

${ }^{1}$ A. A. Barlian, W.-T. Park, J. R. Mallon, Jr., A. J. Rastegar, and B. L. Pruitt, Proc IEEE Inst. Electr. Electron. Eng. 97(3), 513 (2009).

${ }^{2}$ R. He and P. Yang, Nat. Nanotechnol. 1, 42 (2006).

${ }^{3}$ J. S. Milne, A. C. H. Rowe, S. Arscott, and Ch. Renner, Phys. Rev. Lett. 105, 226802 (2010).

${ }^{4}$ A. C. H. Rowe, J. Mater. Res. 29(6), 731 (2014).

${ }^{5}$ R. J. Grow, Q. Wang, J. Cao, D. Wang, and H. Dai, Appl. Phys. Lett. 86, 093104 (2005).

${ }^{6}$ M. Park, H. Kim, and J. P. Youngblood, Nanotechnology 19, 055705 (2008).

${ }^{7}$ R. Rahman and P. Servati, Nanotechnology 23, 055703 (2012).

${ }^{8}$ X. Li, R. Zhang, W. Yu, K. Wang, J. Wei, D. Wu, A. Cao, Z. Li, Y. Cheng, Q. Zheng, R. S. Ruoff, and H. Zhu, Sci. Rep. 2, 870 (2012).

${ }^{9}$ J. Zhao, C. He, R. Yang, Z. Shi, M. Cheng, W. Yang, G. Xie, D. Wang, D. Shi, and G. Zhang, Appl. Phys. Lett. 101, 063112 (2012).

${ }^{10}$ S.-E. Zhu, M. K. Ghatkesar, C. Zhang, and G. C. A. M. Janssen, Appl. Phys. Lett. 102, 161904 (2013).

${ }^{11}$ H.-P. Phan, T. Dinh, T. Kozeki, T.-K. Nguyen, A. Qamar, T. Namazu, N.T. Nguyen, and D. Viet Dao, Appl. Phys. Lett. 109, 123502 (2016).

${ }^{12}$ M. Amjadi, A. Pichitpajongkit, S. Lee, S. Ryu, and I. Park, ACS Nano 8(5), 5154 (2014).

${ }^{13}$ J. Herrmann, K.-H. Muller, T. Reda, G. R. Baxter, B. Raguse, G. J. J. B. de Groot, R. Chai, M. Roberts, and L. Wieczorek, Appl. Phys. Lett. 91, 183105 (2007).

${ }^{14}$ N. M. Sangeetha, N. Decorde, B. Viallet, G. Viau, and L. Ressier, J. Phys. Chem. C 117, 1935 (2013).

${ }^{15}$ P. Siffalovic, L. Chitu, K. Vegso, E. Majkova, M. Jergel, M. Weis, S. Luby, I. Capek, J. Keckes, G. A. Maier, A. Satka, J. Perlich, and S. V. Roth, Nanotechnology 21, 385702 (2010).

${ }^{16}$ L. Yi, W. Jiao, K. Wu, L. Qian, X. Yu, Q. Xia, K. Mao, S. Yuan, S. Wang, and Y. Jiang, Nano Res. 8, 2978 (2015). 
${ }^{17}$ J. L. Tanner, D. Mousadakos, K. Giannakopoulos, E. Skotadis, and D. Tsoukalas, Nanotechnology 23, 285501 (2012).

${ }^{18}$ H. Schlicke, M. Rebber, S. Kunze, and T. Vossmeyer, Nanoscale 8, 183 (2016).

${ }^{19}$ C.-W. Jiang, I.-C. Ni, S.-D. Tzeng, and W. Kuo, Sci. Rep. 5, 11939 (2015).
${ }^{20}$ G. Wang, W. Jiao, L. Yi, Y. Zhang, K. Wu, C. Zhang, X. Lv, L. Qian, J. Li, S. Yuan, and L. Chen, Nanotechnology 27, 405701 (2016).

${ }^{21}$ L. Baker, A. S. Cavanagh, D. Seghete, S. M. George, A. J. Mackus, W. M. M. Kessels, Z. Y. Liu, and F. T. Wagner, J. Appl. Phys. 109, 084333 (2011).

${ }^{22}$ S.-J. Ding, H.-B. Chen, X.-M. Cui, S. Chen, Q.-Q. Sun, P. Zhou, H.-L. Lu,

D. W. Zhang, and C. Shen, Nanoscale Res. Lett. 8, 80 (2013). 